\title{
Contemporary aspects of car sequencing problem in a paint shop
}

\author{
Współczesne problemy sekwencjonowania samochodów \\ na wydziale lakierni
}

\section{JOLANTA KRYSTEK SARA ALSZER ${ }^{\star}$}

DOI: https://doi.org/10.17814/mechanik.2017.7.67
The article presents a problem of car sequencing from the perspective of the paint shop requirements. The issue of determining production orders depending on a color, on which a body is painted, has been considered in the literature several times. However, the assumptions proposed by scientists simplified greatly the analyzed problem in relation to the existing industrial solutions and requirements. The purpose of conducted analysis is to demonstrate a need for a completely new approach to sequencing problem, taking into account an actual structure of a car production line and organization of work in a paint shop.

KEYWORDS: production engineering, sequencing, car production, buffering, CSP

On the world market, there is now a tendency of giving up to make to stock in favor to make to order, which is characteristic of multi-version or multi-product production. Machinery and equipment used in production should have the ability to quickly change over depending on the order. The question arises as to how to organize the production and in what order to execute the orders so that the number of necessary replacements, which translates directly into time and cost of production, is minimal. This problem, referred to as the problem of sequencing, it was widely discussed in the literature, wherein the analyzed process mainly referred to car assembly [1-5].

The car sequencing problem (CSP) is a result of the specificity of the production process itself and the structure of the production line. Each car is manufactured in several successive stages (fig. 1), implemented in the departments of stamping, welding shop, paint shop and assembly.
Body painting is a complex process involving dozens of stages. There are four main phases of painting:

- preparing the body for the painting process,

- painting,

- final machining,

- final quality control.

Irrespective of the manufactured version of the car, each car must pass through all the above stages of painting. For most operations, the color of the body will not matter much from the perspective of process optimization. However, the sequence of the car body determines the number of revolutions of the spray nozzle, which take part in two stages of the painting process, i.e. painting with primer paint and base paint. The reason for this is the occurrence of these paints in different colors (variants). Therefore, considering the characteristic of the vehicle, which is a color, so as to determine the sequence of the chassis to the number of changeovers of the nozzle to a minimum.

\section{Sequencing of cars at the paint shop}

The original problem of car sequencing was defined by Parello et al. [6] in 1986 and it included the problem of sequencing car solely on the assembly department. The solution to this problem was to find a sequence of vehicles equipped with standard and optional components, of which more burdened assembly line in relation to the standard equipment. A fixed sequence of bodywork moving through consecutive workstations of the assembly line was designed to meet the requirements not to exceed the throughput of these stations.

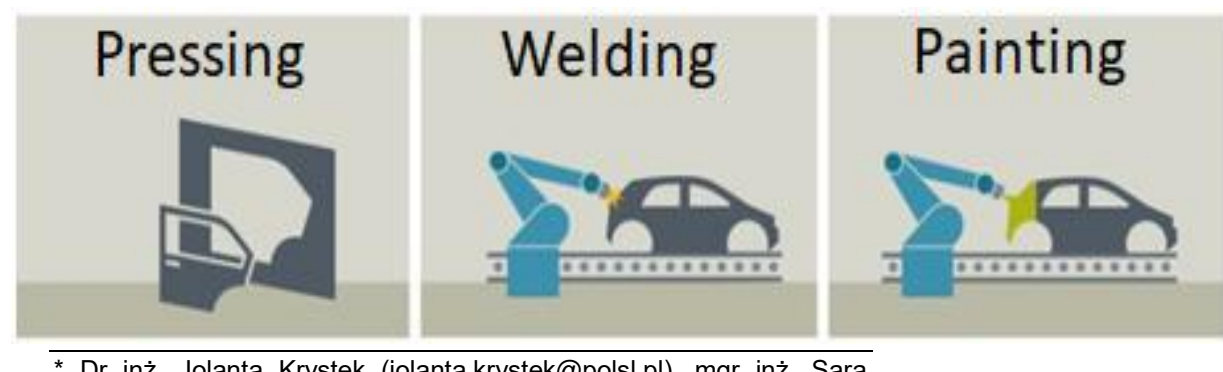

* Dr inż. Jolanta Krystek (jolanta.krystek@polsl.pl), mgr inż. Sara Alszer (sara.alszer@polsı.pl) - Zakład Inżynierii Systemów, Instytut Automatyki, Politechnika Śląska

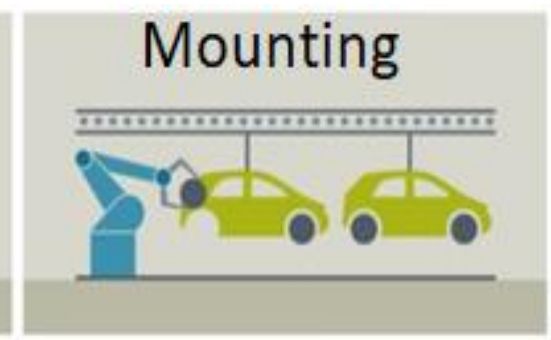

Fig. 1. Stages of car production 
To meet the growing demand for a solution to the problem of sequencing combining the assembly and painting process constraints, the French Society of Operations Research and Decision Analysis organized a competition called ROADEF'2005 Challenge in 2005. It included the fact that the spray nozzle has a finite volume and is assumed to be cleaned after reaching that capacity, which - as with the nozzle cleaning at every color change - results in increased solvent consumption. It was noted that changes color (retooling) result in the extension of production time and affect the increase in production costs. The reason for this is not only the consumption of the solvent, but also the loss of unused ink, which during the changeover remains in the nozzle. Introduction periodic cleanings was to indicate the need to maintain good quality of paints - if the nozzle is not cleaned regularly, residual paint will agglutination (particles sticking together), which result in the body is

\section{Example}

Fig. 2 and fig. 3 show the effect of sequence on the number of color changes under the following conditions:

- the paint shop has one refitted painting robot,

- after the third body, periodic cleaning of the nozzle follows,

- when determining the number of color changes, take into account the changeover occurring at the end of two days of production,

production plan assumes three bodies painted in gray and two bodies in red,

- body of the previous day was painted blue.

In addition, the drawings indicate: periodic cleaning bold straight line, refitting - thin corrugated line.

Sequence A produces three color changes, sequences $B$ and $C$ - two changes, sequence $D$ - one change. In sequences $B$ and $C$, there is a situation where cleaning the nozzle filled with gray and red paint will occur as a result of periodic cleaning. As a result, the remaining ink in the nozzle is lost, because after the cleaning process, the nozzle is reloaded with paint of the same color. Such sequences are particularly disadvantageous from the perspective of minimizing the ink consumption. In sequence $A$, the periodic cleaning is identical to the color change, but it is necessary to reinstall the nozzle twice. The most preferred seems to be sequence $D$, in which there is only one color change.

However, taking into account the requirements of industrial plants, the problem of CSP to the paint shop should be considered from the perspective of minimizing the number of changes not only the color but also the consumption of the lacquer and has to be used to clean the paint nozzle. The NCC component in the objective function is not sufficient - to minimize the solvent consumption is not taken into account. The optimal solution, taking into account the requirements of the industry, is presented in fig. 3 .

Sequence $E$, like sequence $D$, requires only one change of color, but now the change in color occurs at the same time as the periodic cleaning of the nozzle (always occur independent of sequence of colors). This means that in looking for the optimal sequence, should strive for a situation where as many cleanings of the change of the color coincides with the periodic cleanings nozzle. For this purpose, in addition to monitoring the not correctly covered with paint. It was also suggested that when calculating the number of color changes take into account the changeover that occurs at the turn of two days of production, if there is a change of color. All constraints associated with the paint shop have been described with one NCC (number of color changes) variable that specifies the number of color changes, and is included with $w_{\mathrm{cc}}$ as one of the multi-criterion purpose function:

$$
Z=w_{\mathrm{cc}} \cdot N C C+w_{\mathrm{HPRC}} \cdot N H P R C+w_{\mathrm{LPRC}} \cdot N L P R C
$$

The other two variables - NHPRC (number of high priority ratio constraint) and NLPRC (number of low priority ratio constraints) - determined the number of breaches of capacity constraints in the assembly line for options that, respectively, weighed down the assembly line in a large and small way.

number of color changes it is also necessary to analyze instances of periodic cleanings.

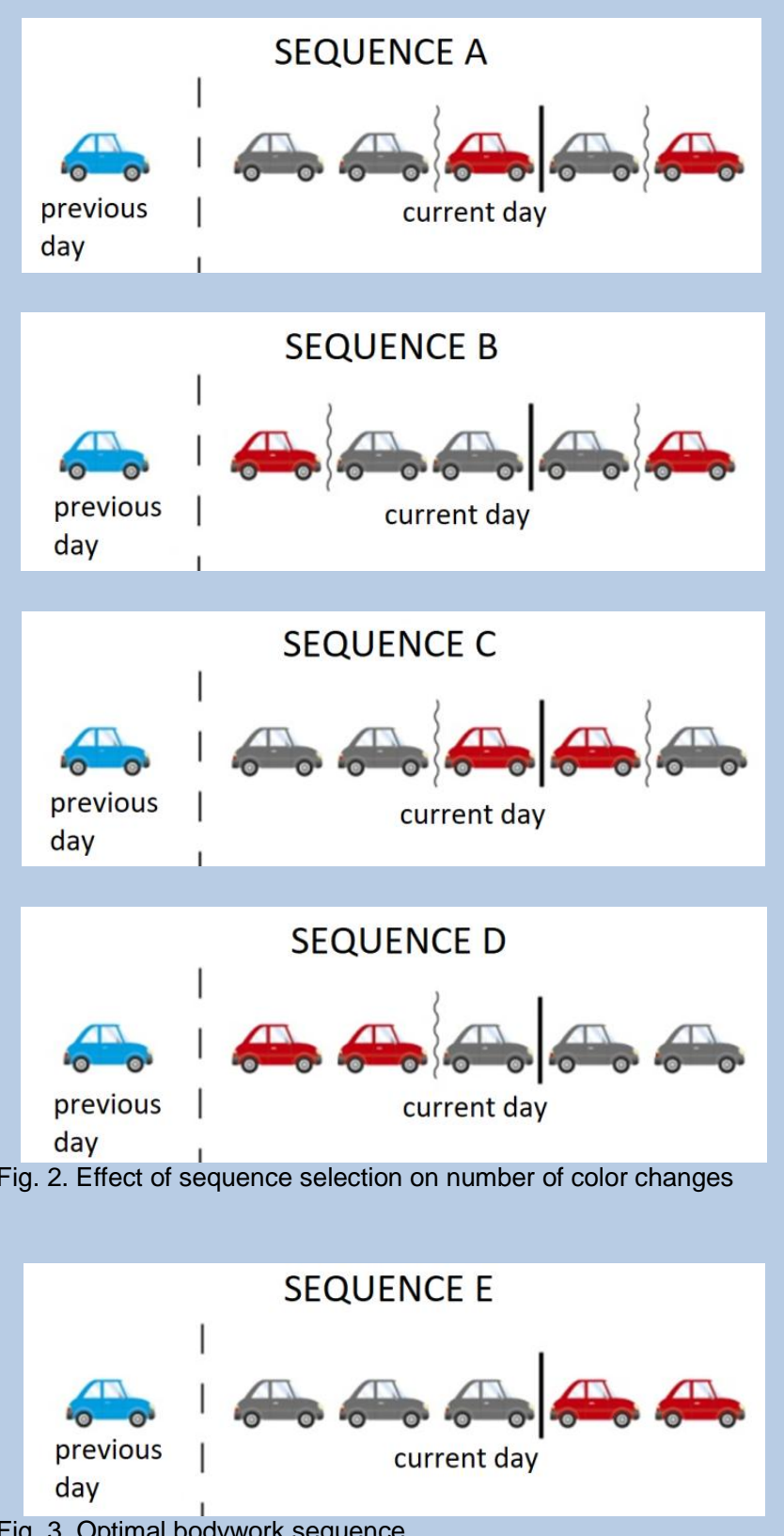




\section{CSPwB problem at paint shop}

The assumption that the purpose of optimizing the process of painting is only to minimize the number of color changes is not acceptable. Among other assumptions that do not reflect the actual organization of work at the department of painting, following are included:

- the use of the paint system based on the filling nozzle paint portions of paint,

- the painting process is minimized to just one operation - coating the base paint,

- treat the process of producing a car as a technological process, in which the sequence of vehicles is determined once before the press department.

Because of the simplifications made, the solutions developed by the researchers have not found direct use in industry. Therefore, the authors of the paper present a modified approach to the problem, hereinafter referred to as Car Sequencing Problem with Buffers (CSPwB).

In CSPwB, it will be applied continuous paint system (fig. 4). Another important argument for abandoning the batch system is the possibility of redundancy of the color change system that feeds individual substances into the nozzle. Then, there is the possibility to reserve one channel for the dominant color, which occurs most often in customer orders. This approach can significantly reduce the number of changeovers of the nozzle and, as a consequence - reducing consumption of paint and solvent. It is essential to use periodic nozzle cleaning to ensure high quality of the painting process.

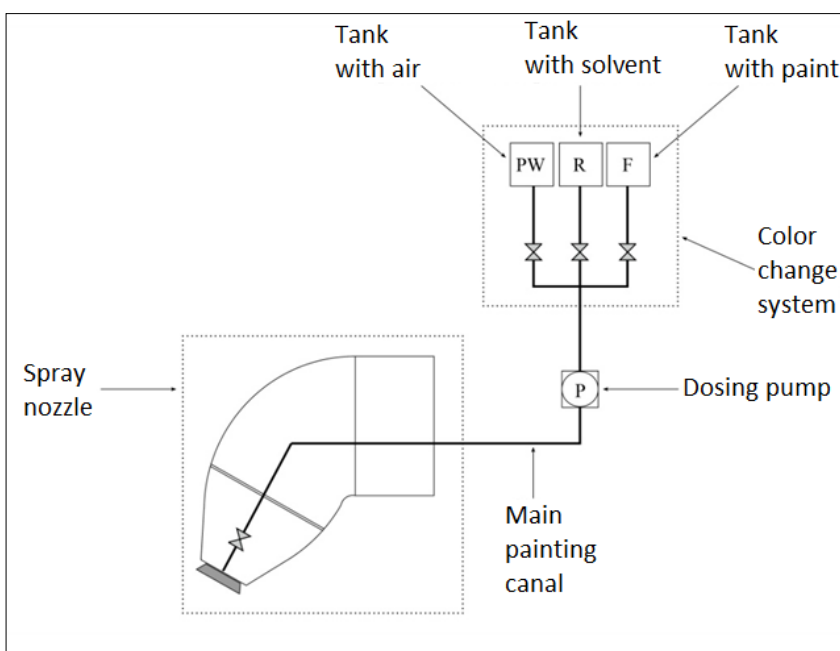

Fig. 4. Structure of the continuous paint system

Another modification is to include CSPwB implemented in stages in the painting process. Of all the painting operations, three main areas can be distinguished: basic painting, base paint and colorless paint - this indicates the stage of the painting process. In the first sequence and the second case of vehicles to be adapted to the requirements of the process step. This is due to the fact that the number of primary colors is usually lower compared to the number of available base colors. Colorless ink occurs only in one variant and is therefore not considered in the present discussion. It is therefore necessary to use such a production line structure, which allows current sequence change and preservation of production continuity. The main advantage of using buffers in the paint shop is: firstly, the separation of the basic paint and base paint processes; secondly, the entire paint department is not independent from the welding department and the assembly department. As a result, the first buffer is used to change the sequence of the welding body leaving department, within the limits of the painting process with base paint, and the second buffer enables the adjustment of the order of the body, assuming optimization of the process with paint base.

\section{Conclusions}

The problem of sequencing bodywork in the paint shop was analyzed over many years. Despite the extension of the original CSP issue with the parameters and limitations of the varnishing process, analysis of the sequencing problem still remained inadequate to the problems of the actual production line. Taking into account the modifications proposed by the authors, the result of the car paint sequencing algorithm on the paint shop should be four sequences: the input/output sequence to/from the storage buffer I and the input/output sequence to/from the storage buffer II. Therefore, the search for a CSPwB solution can be carried out independently for both stages of the painting process. However, when determining the output sequence from buffer $I$, in the case of obtaining several optimal sequences that meet the requirements of the primary coloring process, the selection of sequences may be performed based on the requirements of the paint process of the base paint. A similar situation occurs in the case of an output sequence from the buffer II You can then take into account constraints resulting from the optimization of the assembly process. This, however, does not change the fact that the structure of the buffered line provides the opportunity for independent and ongoing sequencing of the car body at every stage of production.

The work was created in cooperation with ProPoint Ltd. and is financed from BKM-506/RAu1/2016, t. 18.

\section{REFERENCES}

1. Gottlieb J., Puchta M., Solnon C. "A study of greedy, local search and ant colony optimization approaches for car sequencing problems". Applications of Evolutionary Computing. Vol. 2611 of LNCS. Berlin Heidelberg (Germany): Springer-Verlag, 2003, s. 246-257. 2. Puchta M., Gottlieb J. "Solving car sequencing problems by local optimization”. EvoWorkshops. Vol. 2056 of LNCS. Berlin Heidelberg (Germany): Springer-Verlag, 2002, s. 246-257.

3. Zufferey N., Studer M., Silver E. "Tabu search for a car sequencing problem". Proceedings of the 19th International Florida Artificial Intelligence Research Society Conference (FLAIRS 2006). The AAAI Press, CA, 2006, s. 457-462.

4. Gravel M., Gagne C., Price W. "Review and comparison of three methods for the solution of the car-sequencing problem". Journal of the Operational Research Society. 56, 11 (2005): s. 1287-1295.

5. Bautista J., Pereira J., Adenso-Diaz B. "A beam search approach for the optimization version of the car sequencing problem". Annals of Operations Research. 159, 1 (2008): s. 233-244.

6. Parello B.D., Kabat W.C., Wos L. "Job-shop scheduling using automated reasoning: a case study of the car sequencing problem". Journal of Automated Reasoning. 2, 1 (1986): s. 1-42.

7. Solnon C., Cung Van Dat, Nguyen A., Artigues C. "The car sequencing problem: overview of state-of-the-art methods and industrial case-study of the ROADEF 2005 challenge problem".

European Journal of Operational Research. 191, 3 (2008): s. 912 927. 